\title{
Antecedents of software-as-a-service (SaaS) adoption: a structural equation model
}

\author{
Mutlaq B. Alotaibi* \\ Associate Professor, Al Imam Mohammad Ibn Saud Islamic University (IMSIU), Riyadh, Saudi Arabia
}

Received: 30-June-2016; Revised: 18-July-2016; Accepted: 20-July-2016

(C)2016 ACCENTS

\begin{abstract}
With the rapid growth in the use of the internet, software-as-a-service (SaaS) provides unique opportunities that facilitate innovation without upfront investments in technological infrastructure and expertise. Despite its widespread diffusion and economic benefits, attitudes toward SaaS adoption are of paramount importance. This study investigates and models the perception and belief factors that affect the acceptance and use of SaaS. In particular, it examines whether the unified theory of acceptance and use of technology (UTAUT) explains consumer decisions related to the adoption of SaaS. The UTAUT was revised to fit the context of SaaS, by not only incorporating quality of service as a key determinant of behavioral intention, but also by modelling education as a moderator. The study reports a survey of seven hundred and eighty-five $(n=785)$ respondents collected by means of an online questionnaire. Results herein indicates that the acceptance of SaaS relates to several belief factors: performance expectancy, effort expectancy, social influence, facilitating conditions and quality of service. Empirical data support most of the UTAUT relationships.
\end{abstract}

\section{Keywords}

Software-as-a-service, Acceptance, Quality of service, Cloud computing, Saudi Arabia.

\section{Introduction}

Recent advances in the information technology (IT) industry have transformed computing resources so that services are provided in an innovative and continuous manner [1]. Among IT outsourcing mechanisms, a branch of cloud computing, termed SaaS, has risen as a dominant software delivery model, due to its robust and reliable IT infrastructure [2]. A recent report by the international data corporation (IDC) estimated that the SaaS market will reach over $\$ 106$ billion USD in 2016, with forecasts of further rapid growth and great potentials [3]. In this mode, software is basically transformed into a service provided over the internet, leveraging cloud-computing infrastructures and hiding technological complexity [4]. The shift toward webbased platforms for software services brings salient benefits for startups, such as reducing initial costs and facilitating innovation in core businesses [5]. In fact, this platform promotes the growth of SaaS diffusion six times faster than the traditional onpremise software delivery model [1], which implies a radical shift in the software industry [6].

*Author for correspondence

114
Despite the impact of the SaaS model, employee attitudes towards SaaS technology are of great importance, due the opportunities and risks associated with its deployment [7]. It is essential to provide insight into the adoption behaviour of SaaS. Research on SaaS literature has paid extensive attention to studying technological, organizational and environmental factors [8-10]. Another stream of research has considered post-adoption models to study user attitudes and intentions towards SaaS [11, 12]. However, adoption behaviours and attitudes toward cloud-based technologies are built around perceptual beliefs related to effectiveness and ease of use [13]. It is therefore important to investigate user acceptance and use of SaaS technology based on belief factors, particularly in organizational contexts. Few studies have considered investigating user acceptance of SaaS using pre-adoption models. Therefore, this research has identified a gap in the current literature and attempted to fill it by examining the factors affecting technology adoption behaviour in the context of SaaS.

This paper aims to provide insight into the antecedents of SaaS adoption. It further investigates perceptions, attitudes, and potential implications of SaaS adoption. The theoretical background was 
primarily drawn from the unified theory of UTAUT to explain the factors affecting the acceptance and use of SaaS. The contribution of this research is fourfold: (1) it empirically validates the application of UTAUT in the context of SaaS; (2) it expands the UTAUT model, by identifying new constructs and relationships that fit the context at hand, namely quality of service (QoS) and education; (3) it determines the social and cultural aspects that affect the acceptance of SaaS, particularly in developing countries; (4) the outcome of this study is of great relevance for SaaS vendors targeting emerging markets, such as Saudi Arabia.

The remainder of this paper is organized as follows. A detailed theoretical background on software-as-aservice and technology adoption models is provided in section 2. The research model is then presented in section 3 alongside hypotheses development. Details about the research design are provided in section 4 , including research method, instrument development, reliability and validity of the constructs, data collection and sample characteristics. The empirical results are presented in section 5. The discussion, implications of the research, limitations and recommendations for further research are provided in section 6, and finally, section 7 presents the conclusions.

\section{Theoretical background}

\subsection{Software-as-a-service}

SaaS is an emerging business model that reflects a radical shift in the way in which software is delivered to consumers. In fact, it has replaced the traditional software delivery platform, termed on-premises software, with a new web-based model, and hence is initiating a major change in the relationships between vendors and consumers from one-to-one to one-tomany service provision. The difference between SaaS and the traditional approach can be attributed to three main concepts: IT outsourcing, remote hosting and software licensing practices [5]. First, in SaaS deployment models, vendors are held responsible for the reliability of the software delivery platform, IT infrastructure, software development, hardware maintenance, security, user support and data backup. The consumer can guarantee the reliability of the hosted software service through a contract called a service level agreement (SLA). Secondly, the term on-demand software is regularly coupled with SaaS, in which the software is hosted by the vendor, and the consumers merely pay a certain subscription fee to gain access to that software over the web.
Finally, the software is authorized by a single license, in which multiple consumers can access only one version of the software through multi-tenant architectures and technologies. On one hand, the consumer benefits from that by instantly accessing new features added to the software by the vendor. On the other hand, SaaS reduces the complexity of software maintenance and upgrades and opens new directions for vendors to facilitate innovation and improve product offerings. In summary, SaaS is an emerging software delivery model that has great potential, due the shift in thinking that promotes orientation toward deploying software as hosted services.

SaaS brings salient benefits for consumers and vendors alike. In terms of consumer benefits, SaaS lowers upfront investment budgets, decreases the need for in-house IT resources, eliminates softwarerelated overheads and offers ubiquitous computing capabilities [14]. In fact, the initiation of IT departments for small and medium enterprises (SME) can be associated with high costs in terms of initial investment budgets and the development of IT competences and expertise [2]. It is rather more effective to embrace the development of the SaaS model to access a wide range of applications and only pay monthly fees, particularly for businesses that view IT as a supporting function [2]. As mentioned earlier, vendors are responsible for handling ITrelated activities [5]. Therefore, the building of inhouse data centres is seen as an appropriate option to businesses with specific requirements and special needs [14]. In addition, SaaS adopters have instant access to vendor upgrades and new features in the absence of software-related overheads, such configuration management and license complaints [14]. In addition, the omnipresent SaaS model transforms the use of software applications to be independent of time and location [2]. In terms of vendor benefits, shifting to the SaaS model offers economic benefits in software production and distribution, improves revenue and sale predictions and shortens the product development lifecycle [14]. In particular, having production costs distributed among several SaaS clients contributes to decreasing the overheads associated with software distribution, such as licensing management and software piracy [14]. With the SaaS mode, it is much faster to distribute software updates and upgrades, and hence reduce the cost of technical support and maintenance, particularly for minor tasks [14]. In summary, the SaaS model offers several advantages for consumers and vendors. 
Despite the advantages of SaaS adoption, there are several potential risks for both consumers and vendors. For consumers, the decision to adopt a SaaS model involves risks in terms of data recovery and migration, high switching costs, lack of software customization features and integration with legacy software [14]. In fact, SaaS consumers may experience a loss of their data due to inflexibility in migrating the data from one SaaS vendor to another [2]. Another scenario for data loss might be service suspension due to a lack of payment [2]. In addition, switching to a SaaS model may limit customization features and raise concerns relating to integration with legacy software [14]. As for vendor risks, switching to the SaaS model involves risks in terms of high upfront investment in IT infrastructure, diversity of required expertise and skills, management of multiple-suppliers and other performance and scalability concerns [14]. In fact, SaaS vendors incur risks of failure, due to the high cost of initial investment associated with setting up an IT infrastructure and activities related to service delivery and operations [14]. The shift to a SaaS model also calls for the development of a new set of skills, such usage metering and billing, data backup and recovery, security and privacy control and customer support and maintenance [14]. In cases where the vendor decides to collaborate with other SaaS vendors to deliver the service, this entails managing a wide network of multiple suppliers [14]. In addition, there are concerns related to scalability and performance due to concurrent access to the service by several clients [14]. In summary, switching to the SaaS model poses several risks to vendors and consumers alike.

\subsection{Technology adoption theories}

Over the last decade, several models have been empirically examined in order to determine the factors contributing to the acceptance and actual usage of IT. With the aim of synthesizing technology adoption theories, Venkatesh et al. (2003) [15] reviewed eight prior models. The reviewed models were the theory of reasoned action (TRA) [16], the technology acceptance model (TAM) [17], the motivational model (MM) [18], the theory of planned behaviour (TPB) [19], the combined TAM and TPB (C-TAM-TPB) [20], the model of PC utilization (MPCU) [21], the innovation diffusion theory (IDT) [22] and social cognitive theory (SCT) [23]. Based on empirical evidences, the UTAUT model [15] was proposed as a unified model that combines most of the factors within the eight previous models. A recent study by Williams et al. (2015) [24] reviewed and analysed one hundred and seventy-four $(n=174)$ papers in which the UTAUT was exploited as the theoretical foundation for research on technology adoption behaviour [24]. The article revealed that the technologies examined by the UTAUT model were general purpose or business-specific systems [24]. It also examined the significance of the UTAUT relationships, explored the most dominant research methodologies and identified the most frequently used statistical software packages to perform the analyses [24]. In general, the article demonstrated the viability and widespread adoption of the UTAUT model across several contexts, which implies the robustness and trustworthiness of it. In summary, the UTAUT was demonstrated to be a robust and trustworthy theoretical model to examine the acceptance and use of technology across different contexts.

The components of the UTAUT model can be categorized into three main classes: dependent variables, antecedent factors and moderators. First, the dependent variables are behavioural intention (BI) to use and usage behaviour (UB) of the new technology. Secondly, the antecedent factors are performance expectancy (PE), effort expectancy (EE), social influence (SI) and facilitating conditions (FC). The PE refers to the extent to which the user believes that utilizing SaaS in the job setting will be associated with a remarkable improvement in performance [15]. Due to the similarity with other constructs, the PE can be related to several counterparts within different technology adoption models, such as the perceived usefulness and relative advantage within TAM and IDT respectively [15]. The EE denotes the extent to which the user believes that using SaaS is associated with less effort [15]. Drawing upon other adoption models, the concepts of $\mathrm{EE}$ and measurement scales are similar to those for the perceived ease of use construct within TAM or the ease of use construct within IDT [15]. The SI can be defined as the extent to which users believe that important people around them think that they should use SaaS [15]. The SI captures the concept of the subjective norm within several adoption models (TRA, TPB, TAM2) and image within IDT [15]. The FC refers to the extent to which the user believes that SaaS usage is supported by a complete IT infrastructure within the organization [15]. The concept of FC is represented as different constructs within technology adoption models, such as perceived behavioural control and compatibility within TPB and IDT respectively [15]. Finally, the relationships within the UTAUT are theorized as 
being moderated by gender, age, experience and voluntariness of use. In summary, the core components of the UTAUT have been derived from prior research to form a unified view of technology adoption theories.

Prior work highlighted several potential extension techniques that applied to the UTAUT model. For example, Venkatesh et al. (2003) [25] identified three streams of research regarding extension of the theoretical boundaries of the model, namely new context examination, adding new predictors and incorporating new external factors. First, researchers in the first stream of research examined the viability and applicability of the model in contexts other than the original context in which the UTAUT was proposed [25]. Secondly, the other stream of research integrated new predictors within the original model that had a direct association with the dependent variable (i.e. predictors of BI) [25]. Finally, there were several attempts to examine the influence of external factors, particularly with a mediation role for the core predictors of the model [25]. In summary, this line of research suggests that the UTAUT has incurred several alteration attempts, yet there remains scope for further expansion of the theoretical horizons of this robust model.

This research is closely related to studies exploring the attitudes and intentions towards cloud-based services, with a particular focus on SaaS. A few studies have investigated the viability of the UTAUT in the context of cloud computing or SaaS. For example, a study by Alharbi (2014) [26], of user acceptance of cloud computing in Saudi Arabia, proposed a theoretical extension the UTAUT mode to fit the context at hand by incorporating trust as a core predictor of BI [26]. The work was incomplete due to a lack of empirical data, as it proposed the model in the absence of any empirical investigation. Another concern relates to the set-up of the study, as cloud computing is discussed in a very broad sense. As noted by Alotaibi (2014) [27], the use of cloud computing does not reflect all possible perceptions of cloud computing levels, as one end-user might consider Google Docs and its cloud computing features, while professionals might consider organizational infrastructure and platforms [27]. In fact, this lack of focus in prior research calls for employing UTAUT as a trustworthy model to form a robust theoretical background through which to examine user acceptance of one specific layer of cloud computing, namely SaaS. Therefore, it can be argued that a gap in the current literature has been identified, and hence the current study will attempt to fill this gap.

\section{Research model and hypotheses 3.1 Conceptual model}

The UTAUT model forms the initial basis of the current enquiry into user acceptance and use of SaaS. In fact, it has been tailored to expand the theoretical boundaries of the model and to fit the context at hand. The modification of the original model includes incorporating a new construct, replacing a moderator, removing a moderator and adding new relationships. In fact, voluntariness has been excluded from moderators due to the context of the current research, in which SaaS is used in voluntary settings. This argument is consistent with related research in the UTAUT literature [28]. QoS and education have been integrated within the current model, and the following sections discuss related arguments, provide evidence from the current literature and stress the importance of these factors in the context of SaaS.

QoS has been incorporated within technology adoption models, as a key predictor of attitudes and intentions toward different technologies. For example, a study by Lin and Wu (2002) [29] on the user acceptance of web portals found that online service quality has an important role to play in the context of technology adoption behaviour [29]. Another study by $\mathrm{Hu}$ et al. (2009) [30], on the adoption of e-government services, revealed that service quality is a key determinant of intentions towards online services [30]. Furthermore, Akter et al. (2010) [31] investigated the role of service quality on attitudes toward mobile technology in the healthcare sector and found that service quality is a strong predictor of attitude toward mobile technologies. In addition, a study by Çelik and Yilmaz (2011) [32], on the adoption of e-shopping in Turkey, found that integrating service quality within technology adoption models is effective to explain user acceptance. More recently, an investigation by Chang et al. (2015) [33] into the factors affecting the adoption of e-hospital services in Taiwan suggested that service quality can be integrated within technology acceptance models. More importantly, in the context of cloud computing, Alharthi et al. (2015) [34] included service quality variables, such as reliability and bandwidth, among several factors that affect a user's attitudes and intentions toward cloudbased educational services. In summary, QoS has demonstrated to be among the key determinants of 
the attitudes and intentions towards new technologies.

Education has been introduced as moderating factor in several studies carried out in developing countries and has been demonstrated to have a significant effect. Take, for example, the study by Alawadhi and Morris (2008) [35] on the adoption of e-government in Kuwait, which successfully integrated education in a revised UTAUT model. Another study by Gombachika and Monawe (2011) [36], on the attitude and behaviour towards technology in Malawi, revealed the importance of education as a moderating variable in technology acceptance models. More specifically, a study by Alharbi (2012) [37] on cloud computing adoption in Saudi Arabia, using an extended version of TAM, found that attitudes towards cloud computing acceptance are more salient for highly educated individuals. Furthermore, Shi et al. (2013) [38] investigated the acceptance of new technology in the public health sector for the government of Macao and found that education is an important moderator in technology acceptance. More importantly, the study demonstrated that the moderating effect of education is similar to experience in the context of the UTAUT model [38]. Therefore, it can be hypothesized that education can replace experience as a moderating factor. In particular, the effect associated with increased education or experience in the work environment is relatively similar and exists in different aspects, such as growing familiarity and awareness of technology advancements, attitudes towards learning and an increased ability to solve technical problems independently [38]. In summary, based on the theoretical justifications presented, both QoS and education can be incorporated into the UTAUT model. Research hypotheses are presented in the next sections and provide a thorough logical discussion regarding the theoretical basis of each factor. Figure 1 shows the proposed research model.

\subsection{Hypothesis development}

With regard to $\mathrm{PE}$, empirical evidence revealed that $\mathrm{PE}$ is a strong predictor of the intention to use a technology [24]. In particular, research on cloud computing and SaaS supports the finding that PE is a key determinant of intention to use. For example, a study by Wu (2011) [39], on user acceptance of SaaS using a revised version of TAM, found that the effect of PE on intention to use SaaS technology exists. Another study by Alotaibi (2014) [27] conducted research on user intentions and attitudes toward cloud computing in Saudi Arabia and found PE to have a positive effect on intentions to use cloud computing. More recently, a study by Chen (2015) [40] on the adoption of cloud-based SaaS technology in Taiwan found that PE has a strong positive effect on intention to use SaaS technology. Consistent with the UTAUT model [15], the effect of PE on BI is moderated by gender and age. In fact, comparing social roles and responsibilities between males and females indicated that men tend to be more focused on the completion of tasks, particularly for a measure of success [41]. Due to the task-orientation of men, it is hypothesized that the PE for men will be higher than that for women [15]. Similarly, the moderating role of age has been shown to exist in the relationship between $\mathrm{PE}$ and $\mathrm{BI}$ in the context of technology adoption [15]. A study by Alharbi (2012) [37], on the adoption of cloud computing using a modified version of TAM, demonstrated that the moderating effect of age has been found to exist in the context of cloud computing, particularly in Saudi Arabia. The study also recommended recruiting younger workers, due to their tendency to accept cloud computing services and technologies [37]. This can be attributed to several age-related factors that affect the performance of elderly staff members, such as increased external responsibilities and pressures, particularly from the family side [42]. Therefore, it can be argued that PE is positively associated with $\mathrm{BI}$ and the relationship is moderated by both gender and age, and is particularly strong for men and younger workers. To illustrate:

H1: Higher performance expectancy will be associated with higher behavioural intentions to use SaaS.

Hla: The influence of PE on BI will be moderated by gender, such that the effect will be stronger for men. $H 1 b$ : The influence of PE on BI to use SaaS will be moderated by age, such that the effect will be stronger among younger workers.

In terms of the EE effect, evidence from prior research on technology adoption indicated that EE is positively associated with intention to use new technologies [15]. In cloud computing contexts, scholarly research has revealed that such a relationship exists, particularly in the SaaS adoption models. For example, the study by Wu (2011) [39] not only empirically validated this relationship in the context of SaaS, but also demonstrated that EE is a strong predictor of intention to use SaaS, with $\beta=0.499$. Furthermore, a recent study by Chen (2015) [40] supported this notion that EE is positively associated with intention to use SaaS. In line with the UTAUT model [15], the influence of EE on BI is 
moderated by gender and age. As noted earlier, research on gender differences suggest that $\mathrm{EE}$ is higher for women [41]. A recent study by Al-Qeisi (2015) [43], on the viability of UTAUT in nonwestern contexts, supported this notion that the moderating effect of $\mathrm{EE}$ on $\mathrm{BI}$ is stronger for women than men. In terms of the moderating effect of age, research on technology adoption suggested that effort is more salient for older individuals [44]. In particular, the study by Brown et al. (2010) [28] found evidence supporting age moderation of the relationship between EE and BI. Having education integrated into the current model, it was revealed that education has an important moderating role to play in the acceptance and use of new technologies, particularly in cloud computing contexts [37]. This argument is in line with prior research on user acceptance of new technologies in developing countries [35]. In particular, research on technology adoption provided evidence that education moderates the effect of EE on BI [45, 46]. In fact, it was argued that higher education results in a considerable improvement in self-efficacy and remarkable reduction in anxiety [47, 48]. Therefore, EE is theorized to be salient for highly educated individuals $[45,46]$. In summary, it can be hypothesized that EE is a primary antecedent of BI, and the relationship is moderated by gender, age and education, and is particularly strong for women, elderly and highly educated workers. To illustrate:

H2: Higher effort expectancy will be associated with higher behavioural intentions to use SaaS.

H2a: The influence of EE on BI will be moderated by gender, such that the effect will be stronger for women.

H2b: The influence of EE on BI to use SaaS will be moderated by age, such that the effect will be stronger among elderly workers.

H2c: The influence of EE on BI to use SaaS will be moderated by education, such that the effect will be stronger among highly educated workers.

With regard to the SI role, SI represents a key determinant of intention to use new technologies [24]. In fact, beliefs and behaviours of individuals who intend to comply with expectations of others are subject to alteration, as a response to social pressure [49]. Consistent with the UTAUT model, the relationship between $\mathrm{SI}$ and $\mathrm{BI}$ is moderated by gender and age [24]. Research on technology adoption found evidence supporting the argument that gender has a moderating role in the relationship between SI and BI. For example, $\mathrm{Hu}$ et al. (2010)
[50] provided empirical evidence that the effect of SI on BI is moderated by gender among Arabian workers. In general, recent adoption theories suggest that SI is more salient for women, and particularly in Saudi Arabia [51]. This can be attributed to the Saudi women's perceptions and behaviours that usually tend to comply with rigid traditions and social pressures more than their own independent assessment [51]. In terms of the moderating effect of age, the effect of SI increases among elderly workers, due to their sensitivity to others' opinions [15]. As mentioned earlier, education has a moderating role in the relation between SI and BI, due to the tendency of educated workers to shape their attitudes toward technology adoption under great social pressures, particularly in non-western contexts [46]. In fact, Su et al. (2013) [45] found that SI is relevant for highly educated individuals, because they are viewed as knowledgeable in their social structure, and hence are more sensitive to others' expectations. In summary, it can be hypothesized that BI can be determined by SI, and the relationship is moderated by gender, age and education, and is particularly strong for women, the elderly and highly educated workers. To illustrate:

H3: Higher social influence will be associated with higher behavioural intentions to use SaaS.

H3a: The influence of SI on BI will be moderated by gender, such that the effect will be stronger for women.

H3b: The influence of SI on BI to use SaaS will be moderated by age, such that the effect will be stronger among elderly workers.

H3c: The influence of SI on BI to use SaaS will be moderated by education, such that the effect will be stronger among highly educated workers.

In accordance with the UTAUT model [15], FC is a direct determinant of UB. Prior research supports the notion that FC is a strong predictor of UB [52]. It is worth noting that the effect of FC on UB is moderated by age [15]. In fact, the FC is more salient among elderly workers, due to their tendency to seek help and support in order to accomplish their jobrelated tasks [53]. In terms of the role of education, few studies have investigated the moderating effect of education on the relationship between FC and UB. However, this study modelled education as a replacement of experience in the original UTAUT model, which was found to be significant for inexperienced workers [15]. Therefore, it can be hypothesized that the effect of FC decreases with education, and hence is stronger for lower education levels. This argument is supported by regular 
observations that workers with lower education levels are more likely to seek help and assistance in using new technologies, compared with highly educated workers [54]. In summary, it can be hypothesized that FC is positively associated with UB, and the relationship is moderated by age and education, and is particularly strong for elderly and lower-educated workers. To illustrate:

H4: Facilitating conditions will be positively associated with usage behaviour of SaaS.

H4a: The influence of FC on UB of SaaS will be moderated by age, such that the effect will be stronger among elderly workers.

H4b: The influence of FC on UB of SaaS will be moderated by education, such that the effect will be stronger among lower-educated workers.

QoS refers to the extent to which the user believes that using SaaS is usable, reliable, responsive and customizable [55]. The concept of QoS is represented by different constructs within technology adoption models, such as e-quality, quality of the internet and online service quality. Evidence from prior research on technology adoption indicated that QoS is a key predictor of intention to use new technologies [55, 56]. More recently, research on cloud computing revealed that such relationships do exist [57]. Therefore, it can be hypothesized that QoS has a positive influence on intention to use SaaS. To illustrate:

H5: Higher quality of service will be associated with higher behavioural intention to use SaaS.

Behavioural intention (BI) is a common construct among all technology adoption models, as it is consistently theorized to be a direct antecedent of UB [15]. Therefore, it can be hypothesized that BI has a positive effect on SaaS usage behaviour. To illustrate:

H6: Higher behavioural intention to use SaaS will be associated with higher usage behaviour.

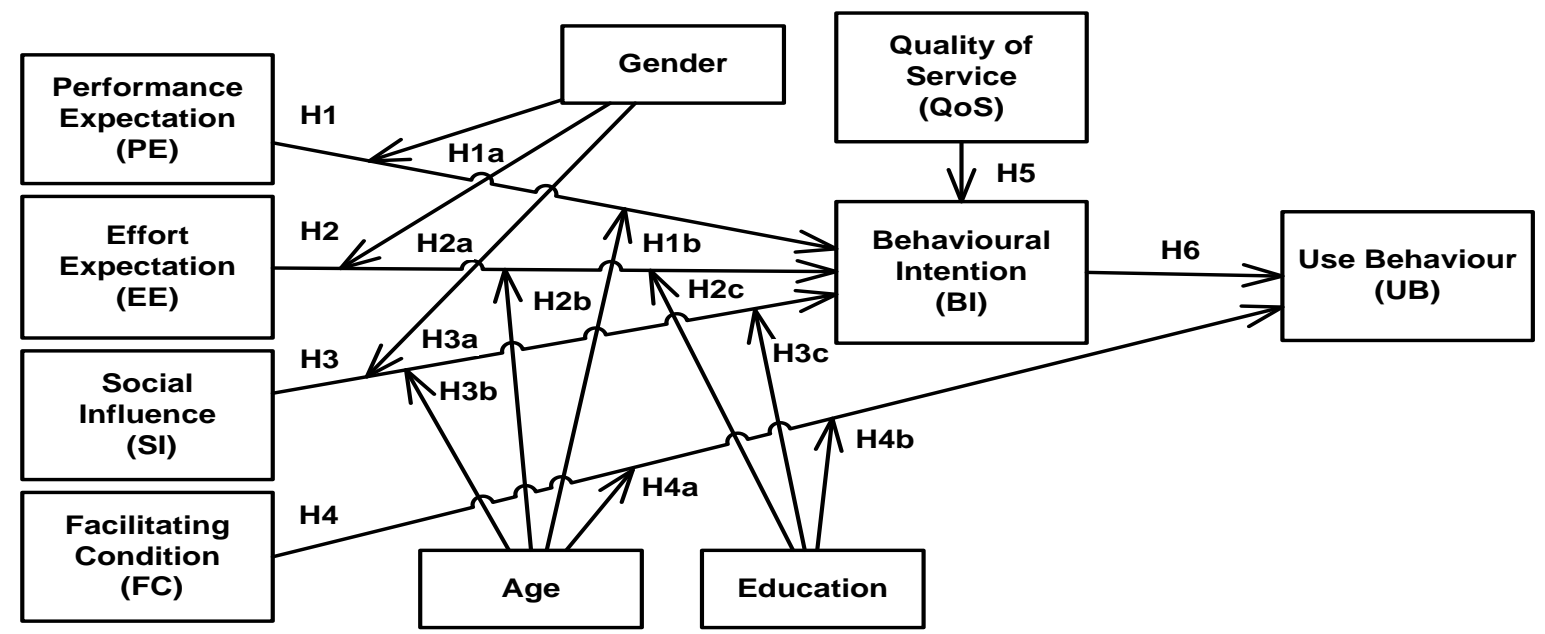

Figure 1 Proposed research model (adapted from [15])

\section{Research design}

\subsection{Research method}

This research is quantitative [58], whereby research hypotheses are empirically verified. With the research model hypothesized, the structural equation modelling (SEM) analysis technique was employed to provide a quantitative test [59]. This involved using survey methods to collect empirical data, and in particular, develop an instrument as a method of measurement.

\subsection{Instrument design}

A great deal of related research has been reviewed to develop a research instrument especially for this study. The latent variables were adopted from prior studies, yet the associated items were tailored to the fit the context of SaaS. In order to validate the content, a panel of experts was established. Initially, a draft version of the questionnaire was proposed based on prior research, and a pilot study was conducted to validate the instrument.

The experts observed volunteer participants completing the draft questionnaire and provided 
several comments related to the content validity, resulting in minor sentence structure modifications. The experts also recommended supplementing the English version of the questionnaire with an Arabic translation in an interactive and simple manner.

The structure of the instrument has three major sections: demographics, SaaS adoption and a comments section. First, the participants were asked to answer four demographic questions: gender, age, IT background and education. As noted by Gombachika and Monawe (2011) [36], education is measured by formal qualifications. Second, the constructs and measures in the SaaS adoption section were adopted from the UTAUT model, as shown in Table 1. The responses for each statement were measured by a seven-point Likert-type scale ranging from strongly disagree to strongly agree [60]. The newly incorporated construct (QoS) was measured by SaaS QoS attributes, namely performance, reliability, modifiability and usability [61]. Finally, participant notes and comments were collected in the comments section. In summary, a research instrument comprising three sections was devised especially for this study as a means of data collection. Using the SEM, the reliability and convergent validity of the constructs were examined by Cronbach's alpha $(\alpha)$, average variance extracted (AVE) and composite reliability (CR). Table 2 shows the reliability and convergent validity measures for the constructs. Overall, the measures in the structural model exhibit adequate reliability and convergent validity. In particular, most of the factor loadings exceeded the recommended 0.7 level [62], with measures ranging from 0.651 to 0.873 . Although the factor loadings of two items (namely BI2=0.651 and QoS4=0.698) were lower than 0.7 , the measures of factor loading can be regarded as adequate at 0.55 [63]. Furthermore, the measures for Cronbach's alpha exceeded the acceptable 0.7 level [64], ranging from 0.744 to 0.856. Similarly, the AVE measures for all constructs exceeded the benchmark of 0.5 [64], with values falling between 0.506 and 0.670 . The CR showed a similar picture, as all CR estimates were found to be greater than the critical value of 0.6 [64], with values ranging between 0.705 and 0.871 . Table 3 shows the discriminant validity of the constructs. In fact, the estimates indicate that the scales were not correlated, as the higher measures have been shown to be associated with the construct being inter-correlated with itself [65]. Therefore, it can be said that discriminant validity of the constructs is supported. In summary, results herein support the reliability and validity (both convergent and discriminant validity) of the constructs.

Table 1 Research instrument

\begin{tabular}{lll}
\hline & Item & Measure \\
\hline PE & PE1 & Using software-as-a-service improves my performance [39]. \\
& PE2 & Using software-as-a-service advances my competitiveness [39]. \\
& PE3 & The functionality of software-as-a-service satisfies me [39]. \\
EE & PE4 & Using software-as-a-service enables me to do my tasks faster [39]. \\
& EE1 & The procedure of using software-as-a-service is understandable [39]. \\
& EE2 & It is easy to learn using software-as-a-service [39]. \\
& EE3 & It is easy to make use of software-as-a-service [39]. \\
& EE4 & Overall, I believe that software-as-a-service is easy to use [15]. \\
SI & SI1 & Mass media influences me to use software-as-a-service [39]. \\
& SI2 & Expert opinions influence me to use software-as-a-service [39]. \\
& SI3 & Word-of-mouth influences me to use software-as-a-service [39]. \\
& SI4 & People who influence my behaviour think that I should use software-as-a-service [15]. \\
FC & FC1 & I have the resources necessary to use software-as-a-service [15]. \\
& FC2 & I have the knowledge necessary to use software-as-a-service [15]. \\
& FC3 & A specific person (or group) is available for assistance with software-as-a-service difficulties [15]. \\
QoS & QoS1 & I believe software-as-a-service is responsive [61]. \\
& QoS2 & I believe software-as-a-service is reliable [61]. \\
& QoS3 & I believe software-as-a-service is customizable [61]. \\
& QoS4 & I believe software-as-a-service is usable [61]. \\
BI & BI1 & I have plans to us software-as-a-service [15]. \\
& BI2 & I predict I will use software-as-a-service during the next three months [15]. \\
& BI3 & Overall, I intend to use software-as-a-service in the future [39]. \\
UB & UB1 & I have used different types of software-as-a-service applications [51]. \\
& UB2 & I am regularly using software-as-a-service [51].
\end{tabular}


Mutlaq B. Alotaibi

Table 2 Construct reliability and convergent reliability measures

\begin{tabular}{llllll}
\hline & Item & Loading & $\boldsymbol{\alpha}$ & AVE & CR \\
\hline PE & PE1 & 0.801 & 0.856 & 0.602 & 0.858 \\
& PE2 & 0.802 & & & \\
& PE3 & 0.766 & & & \\
EE & PE4 & 0.732 & & & \\
& EE1 & 0.832 & 0.842 & 0.622 & 0.868 \\
& EE2 & 0.765 & & & \\
& EE3 & 0.757 & & & \\
& EE4 & 0.798 & & & \\
SI & SI1 & 0.743 & 0.820 & 0.629 & 0.871 \\
& SI2 & 0.808 & & & \\
& SI3 & 0.827 & & & \\
& SI4 & 0.792 & & & \\
FC & FC1 & 0.787 & 0.781 & 0.670 & 0.858 \\
& FC2 & 0.792 & & & \\
& FC3 & 0.873 & & & \\
QoS & QoS1 & 0.737 & 0.762 & 0.517 & 0.811 \\
& QoS2 & 0.713 & & & \\
& QoS3 & 0.728 & & & \\
& QoS4 & 0.698 & & & \\
BI & BI1 & 0.715 & 0.752 & 0.506 & 0.754 \\
& B12 & 0.651 & & & \\
& BI3 & 0.763 & & & \\
UB & UB1 & 0.751 & 0.744 & 0.544 & 0.705 \\
& UB2 & 0.724 & & & \\
\hline
\end{tabular}

Table 3 Discriminant validity of the constructs

\begin{tabular}{llllllll}
\hline & SI & BI & UB & FC & EE & PE & QoS \\
\hline SI & 0.79 & & & & & & \\
BI & 0.64 & 0.71 & & & & & \\
UB & 0.35 & 0.51 & 0.74 & & & & \\
FC & 0.58 & 0.62 & 0.65 & 0.82 & & & \\
EE & 0.64 & 0.55 & 0.47 & 0.77 & 0.79 & & \\
PE & 0.77 & 0.59 & 0.31 & 0.47 & 0.62 & 0.78 & \\
QoS & 0.61 & 0.63 & 0.38 & 0.58 & 0.57 & 0.49 & 0.72 \\
\hline
\end{tabular}

\subsection{Data collection}

The process of data collection was carried out by means of an online questionnaire, due to its simplicity and effectiveness. Another reason for using an online questionnaire was to ensure that participants were all internet users, and hence potential SaaS consumers. Within this process, a sample comprising one hundred and eighty $(n=180)$ organizations was identified, so as to collect employees' electronic mail addresses (e-mail addresses) for potential participants in this study. After identifying the responsible department for email lists in each organization, such as the IT and/or personnel department, the department manager was contacted and requested to provide e-mail lists. Only seventy-two $(n=72)$ organizations provided their email lists. As a result, a sample of three thousand, six hundred and ninety-five $(n=13,695)$ was identified as a list of potential participants representing employees of the private and public sectors. The potential participants were initially contacted, with an e-mail introducing the purpose of the study, and requesting and appreciating their participation. Three hundred and fifty-eight $(n=385)$ e-mails failed to reach the participants, due to incorrect addresses. One week later, another batch of e-mails was sent to the remaining audience, with a link to the actual online questionnaire. The message introduced the concept of SaaS and provided examples of online services provided through cloud computing. In fact, one thousand, two hundred and fifty-three $(n=1,253)$ participants completed the questionnaire. The responses were examined and checked for validity and completeness. Only seven hundred and eightyfive $(n=785)$ responses qualified as valid and complete, resulting in a response rate of $16.96 \%$. In summary, data was gathered by means of online survey for employees working for different private and public organizations in Saudi Arabia.

\subsection{Sample characteristics}

Using a survey sample collected from 785 workers, results indicated that almost half of participants were middle aged, with ages ranging from 25 to 34 . The majority were well educated; in particular, those holding a bachelor degree represented $57.7 \%$ of the sample. The sample showed a delegate balance between the two genders, as the sample was divided equally between male and female workers. It was noteworthy that almost $70 \%$ of the sample had a solid IT background. Table 4 shows other demographics.

Table 4 Sample characteristics

\begin{tabular}{llll}
\hline Respondent Demographics & Frequency & Percent \\
Number of respondents & 785 & 100 \\
Gender & Female & 389 & 49.6 \\
Background & Male & 396 & 50.4 \\
& Non- & 238 & 30.3 \\
& technology & & \\
& Computing & 547 & 69.7 \\
\&technology & & \\
Age & Less than 17 & 49 & 6.2 \\
& years & & \\
& $18-24$ & 240 & 30.6 \\
& 25-34 & 388 & 49.4 \\
& $35-44$ & 78 & 9.9 \\
Education & 45-54 & 19 & 2.4 \\
& 55 and above & 11 & 1.4 \\
& High school or & 104 & 13.2 \\
& under & & \\
& Two-year & 64 & 8.2 \\
& diploma & & \\
& Bachelor & 453 & 57.7 \\
& Master & 129 & 16.4 \\
PhD & 35 & 4.5 \\
\hline
\end{tabular}




\section{Empirical results}

The fit of the structural model was examined through several indices, as shown in Table 5. In fact, seven $(n=7)$ quality-of-fit measures were utilized, and compared against recommended thresholds for good fit. Results demonstrated good fit, as the seven fit indices for the structural model satisfied the model fit requirements. First, the ratio of chi-square/degree of freedom $\left(\chi^{2} / \mathrm{df}\right)$ was greater than the critical value $(\chi 2 / \mathrm{df}<3.00)$ [66]. Secondly, the Root Mean Square Error Approximation (RMSEA) was estimated to be lower than the recommended benchmark (RMSEA $\leq 0.08)$ [67]. Thirdly, the estimate for Standardized Root Mean Residual (SRMR) indicated a good fit [67]. Finally, the estimates for Incremental Fit Index (IFI), Comparative Fit Index (CFI), Tucker Lewis Index (TLI) and Normed Fit Index (NFI) were greater than the benchmark of 0.90 [68], with values of $0.944,0.943,0.928$ and 0.917 , respectively. In summary, the results obtained from seven quality-offit measures indicated a good fit for the structural model.

Figure 2 presents results of the structural model, showing both the path coefficients $(\beta)$ and the explained variance $\left(\mathrm{R}^{2}\right)$. In accordance with criteria for model adequacy [63], all determinants in the current model individually accounted for more than the benchmark of $1.5 \%$ of the variability in its associated construct. Similarly, the estimates for $\mathrm{R}^{2}$ were adequate among all constructs, with $\mathrm{R}^{2}$ values exceeding the acceptable 0.10 level. It can be seen from the figure that the constructs of PE, EE, SI and QoS were core determinants of BI with a predictive ability of $81 \% \quad\left(\mathrm{R}^{2}=0.81\right)$. In addition, it was demonstrated that the FC and $\mathrm{BI}$ determines UB with a predictive ability of $26 \%\left(\mathrm{R}^{2}=0.26\right)$. In summary, the BI had the highest exploratory power among the constructs. With regard to path analysis, the structural model supported most of the propositions and showed statistically significant results. Excluding the moderating effect of gender on the relationship between SI and BI, all path analysis results showed statistical significance at the 0.001 confidence level.

Table 5 Model-fit indices

\begin{tabular}{|c|c|c|}
\hline Fit indices & $\begin{array}{l}\text { Structural } \\
\text { model }\end{array}$ & Benchmark \\
\hline $\begin{array}{l}\text { Chi-square/degree } \\
\text { freedom }\left(\chi^{2} / \mathrm{df}\right)\end{array}$ & 2.971 & $<3.00[66]$ \\
\hline $\begin{array}{l}\text { Root Mean Square Error } \\
\text { Approximation (RMSEA) }\end{array}$ & 0.050 & $\leq 0.08[67]$ \\
\hline $\begin{array}{l}\text { Standardized } \quad \text { RMR } \\
\text { (SRMR) }\end{array}$ & 0.074 & $\begin{array}{l}\text { the smaller } \\
\text { the better } \\
{[67]}\end{array}$ \\
\hline Incremental fit index (IFI) & 0.944 & $\geq 0.90[68]$ \\
\hline $\begin{array}{l}\text { Comparative fit index } \\
\text { (CFI) }\end{array}$ & 0.943 & $\geq 0.90[68]$ \\
\hline Tucker Lewis Index (TLI) & 0.928 & $\geq 0.90[68]$ \\
\hline Normed Fit Index (NFI) & 0.917 & $\geq 0.90[68]$ \\
\hline
\end{tabular}

In particular, the influence of PE on BI was found to be positive (standardized $\beta=0.14$ ). It was also shown that the relationship between $\mathrm{PE}$ and $\mathrm{BI}$ was moderated by gender (with a path coefficient of standardized $\beta=0.30$ ). Age was demonstrated to have a moderating effect on the relationship between PE and BI (with a path coefficient of standardized $\beta=$ 0.14). Furthermore, the effect of EE on BI was positive (with a standardized path coefficient of standardized $\beta=0.13)$.

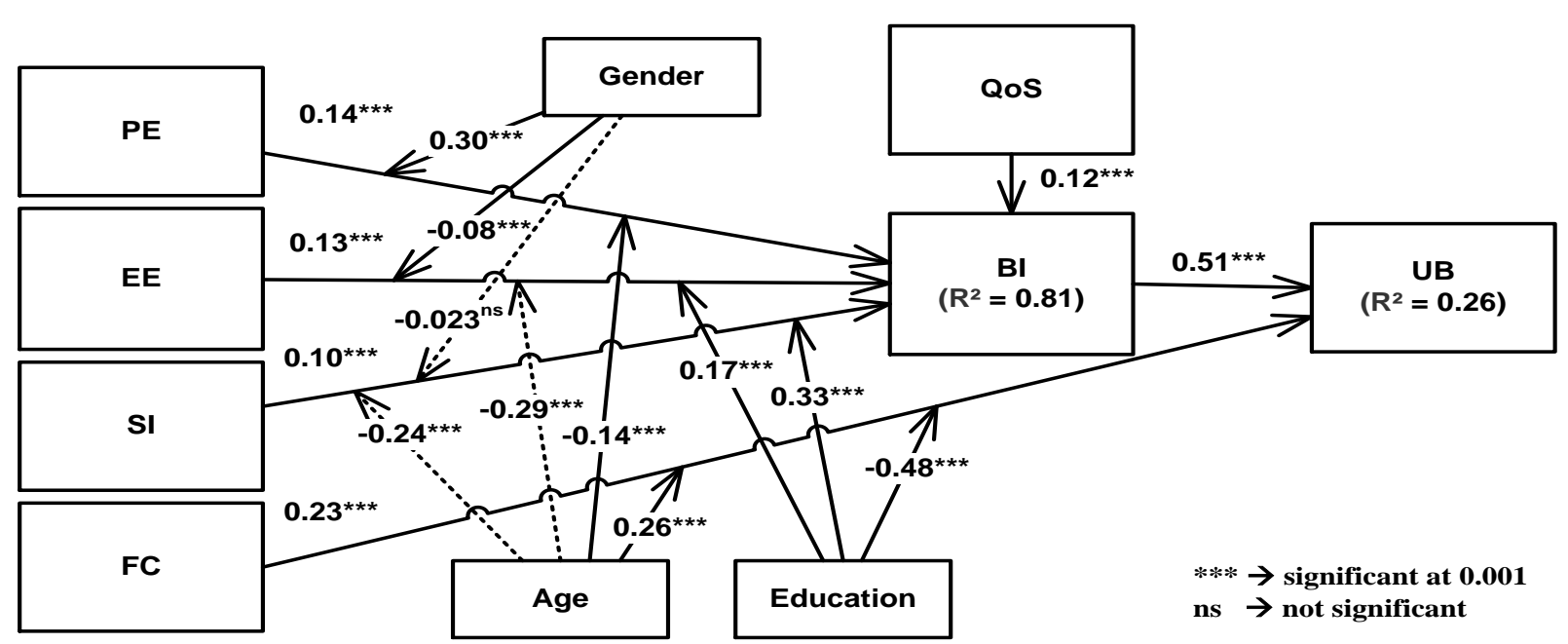

Figure 2 Results of the structural model 
With a statistical significance, the relationship between $\mathrm{EE}$ and $\mathrm{BI}$ was moderated by gender, age and education with standardized path coefficients of $0.08,-0.29$ and 0.17 , respectively. In terms of SI, the influence of SI on BI was shown to be positive (with a path coefficient of standardized $\beta=0.10$ ). In particular, the effect of SI on BI was moderated by both age and education with standardized path confidents of -0.24 and 0.33 respectively. Contrary to the proposition, gender has no moderating effect on the relationship between SI and BI (with a path coefficient of standardized $\beta=-0.023$ ). In addition, the effect of QoS on BI was demonstrated to be significant, with a positive direction and a path coefficient of standardized $\beta=0.12$. In terms of the paths related to the UB, the influence of FC on UB reached statistical significance (with a positive path coefficient of standardized $\beta=0.23$ ). Within this relationship between FC and $\mathrm{UB}$, the moderating effect of age and education was also significant, with standardized path coefficients of 0.26 and -0.48 respectively. Moreover, the effect of BI on UB was found to have a positive path coefficient (standardized $\beta=0.51$ ). In summary, the path analysis showed different influence patterns that determine the relationship between dependent and independent variables, such as positive, negative or nonsignificant relationships.

It was noteworthy that some of the results reversed the direction of the relationships proposed in the current structural model; however, the next section will shed more light on such results.

\section{Discussion}

For the purpose of identifying the factors affecting acceptance and use of SaaS, this paper revealed that SaaS adoption behaviour can be determined by PE, EE, SI, FC and QoS. This research highlighted the belief factors that determine the acceptance of SaaS by examining sixteen hypotheses. Table 6 presents a review of the hypotheses testing results, along with their associated interpretations. At a glance, most of the hypotheses were supported, except for that related to the moderating effect of gender on the relationship between SI and BI. Building upon hypotheses acceptance, several managerial implications can be derived. For example, the first hypothesis $(\mathrm{Hl})$ was supported, as shown in the table, and stated that PE has a direct effect on BI in the context of SaaS. Not only that, but also the effect of PE on BI was moderated by gender and age, particularly so for men and younger workers. Therefore, it can be said that the sub-hypotheses Hla and Hlb were also supported. This can be attributed to the tendency of men and younger workers to be more focused on task accomplishment and being concerned about measures of success, compared to women and elderly workers. This finding is consistent with empirical evidence from prior research [15]. In fact, SaaS vendors should consider that SaaS services have a positive role to play in improving worker performance, particularly with a male-oriented social structure and younger workforce, like the Saudi market. Therefore, marketing managers should produce effective marketing campaigns that highlight the potential performance-related advantages of SaaS solutions.

Table 6 Review of hypotheses testing results

\begin{tabular}{|c|c|c|c|c|c|}
\hline$\#$ & Path & $\boldsymbol{\beta}$ & t-value & Accepted? & Explanations \\
\hline$H 1$ & $\mathrm{PE} \rightarrow \mathrm{BI}$ & $0.14 * * *$ & 8.938 & yes & The effect is direct \\
\hline$H 1 a$ & Gender $\rightarrow \mathrm{PE} \rightarrow \mathrm{BI}$ & $0.302 * * *$ & 19.294 & yes & Salient for men \\
\hline$H 1 b$ & $\mathrm{Age} \rightarrow \mathrm{PE} \rightarrow \mathrm{BI}$ & $-0.141 * * *$ & -9.01 & yes & Salient for younger workers \\
\hline$H 2$ & $\mathrm{EE} \rightarrow \mathrm{BI}$ & $0.126 * * *$ & 8.047 & yes & The effect is direct \\
\hline$H 2 a$ & Gender $\rightarrow \mathrm{EE} \rightarrow \mathrm{BI}$ & $-0.083 * * *$ & -5.306 & yes & Salient for women \\
\hline$H 2 b$ & $\mathrm{Age} \rightarrow \mathrm{EE} \rightarrow \mathrm{BI}$ & $-0.291 * * *$ & -18.612 & No & Reverse direction \\
\hline$H 2 c$ & Education $\rightarrow \mathrm{EE} \rightarrow \mathrm{BI}$ & $0.171 * * *$ & 10.911 & yes & Salient for high education \\
\hline$H 3$ & $\mathrm{SI} \rightarrow \mathrm{BI}$ & $0.10 * * *$ & 6.385 & yes & The effect is direct \\
\hline$H 3 a$ & Gender $\rightarrow \mathrm{SI} \rightarrow \mathrm{BI}$ & $-0.023^{\mathrm{ns}}$ & -1.489 & No & $\mathrm{p}=0.136$ \\
\hline$H 3 b$ & $\mathrm{Age} \rightarrow \mathrm{SI} \rightarrow \mathrm{BI}$ & $-0.239 * * *$ & -15.264 & No & Reverse direction \\
\hline$H 3 c$ & Education $\rightarrow$ SI $\rightarrow$ BI & $0.326 * * *$ & 20.85 & yes & Salient for high education \\
\hline$H 4$ & $\mathrm{FC} \rightarrow \mathrm{UB}$ & $0.225 * * *$ & 14.373 & yes & The effect is direct \\
\hline $\mathrm{H} 4 \mathrm{a}$ & Age $\rightarrow$ FC $\rightarrow$ UB & $0.263 * * *$ & 16.813 & yes & Salient for elderly workers \\
\hline$H 4 b$ & Education $\rightarrow \mathrm{FC} \rightarrow \mathrm{UB}$ & $-0.481 * * *$ & -30.72 & yes & Salient for lower education \\
\hline H5 & $\mathrm{QoS} \rightarrow \mathrm{BI}$ & $0.122 * * *$ & 7.771 & yes & The effect is direct \\
\hline H6 & $\mathrm{BI} \rightarrow \mathrm{UB}$ & $0.506 * * *$ & 16.412 & yes & The effect is direct \\
\hline
\end{tabular}


Furthermore, it can be seen from the table that the second hypothesis (H2) was supported. This hypothesized that EE has a direct positive effect on BI. The influence of EE on BI was demonstrated as being moderated by gender, age and education, particularly for women, younger and highly educated workers. This can be attributed to the typical social roles and responsibilities of women that tend to be associated with increasing family pressures. In addition, increased levels of education reduced computer anxiety and increased self-efficacy, and hence improved effort expectancy. Therefore, it can be said that the sub-hypotheses $H 2 a$ and $H 2 c$ were supported. This observation is in line with empirical results from related studies [15, 45]. It is noteworthy that the moderating effect of age on the relationship between EE and BI had a reverse direction, which was hypothesized as being salient for elderly workers in the first place. Therefore, it can be said that subhypothesis $H 2 b$ was rejected. Although this finding contradicted the UTAUT model [15], it can be attributed to the negative association between age and attitudes towards cloud computing in the context of Saudi Arabia, as obtained from empirical evidence from prior research [37]. This provides another example of managerial implications resulting from the effort-related concerns associated with women and younger workers, as well as the role of SaaS, to reduce the effort of highly educated workers. In fact, it is essential for IT managers to provide customized SaaS solutions that facilitate remote work environments to accommodate effort-related requirements of female employees. In addition, the omnipresent SaaS facilitates recruiting consultancy teams of experts and highly educated individuals, who can work from a distance and collaborate with current employees at a convenient time.

In addition, the table showed that the third hypothesis (H3) was supported; this stated that SI has a direct positive effect on BI. In particular, the effect of SI on BI was moderated only by age and education, particularly for younger and highly educated workers. In fact, the acceptance and rejection status of the subhypotheses associated with the SI-BI relationship showed a different picture, as one sub-hypothesis was fully supported, namely $H 3 c$, which related to the moderating effect of education. This can be attributed to the sensitivity of highly educated workers toward others' opinions, because they are viewed as knowledgeable and hence expected to shape their attitudes toward technology adoption under great social pressures. This finding was compatible with evidence from prior research $[45,46]$. Sub- hypothesis $H 3 a$ was rejected due to insignificant results and sub-hypothesis $H 3 b$ was also rejected, due to the reverse direction (these two findings have theoretical implications that will be discussed later). In addition, it can be seen from the table that the fourth hypothesis (H4) was supported, which theorized that $\mathrm{FC}$ has a direct positive influence on UB. The two associated sub-hypotheses were also supported, namely $H 4 a$ and $H 4 b$. In fact, the moderating effect of age and education on the relationship between FC and UB was found to be salient for elderly and lower-educated workers, due to their constant need for technical help and support. This finding is consistent with empirical evidence from prior research $[15,54]$. Therefore, it is rather important for IT managers to enrich help materials and facilitate IT support in order to enable the effective use of SaaS technology. This can be achieved by offering regular training sessions, webbased helpdesk software and on-site technical support.

Furthermore, hypothesis $H 5$ was supported by the data, demonstrating that $\mathrm{BI}$ has a direct positive effect on UB. This finding was compatible with the UTAUT model [15]. It is noteworthy that this relationship recorded the highest estimate for the path coefficient (standardized $\beta=0.506$ ), amongst all supported relationships investigated during the course of this research. Finally, hypothesis H6 was supported, which stated that QoS has a direct positive influence on BI. This finding was compatible with several prior related studies [55-57]. As mentioned earlier, the QoS construct was introduced by the current study to examine its role in the usage and acceptance of SaaS. Therefore, it can be said that QoS can be integrated within the UTAUT as a key determinant of BI. This can be attributed to the nature of the SaaS, as an internet-based technology that relies on a cloud-computing infrastructure to deliver software services to enterprise users. Having that role revealed, IT managers should embrace the development of hybrid cloud-computing models that allow private data storage and domestic computing services with the ability to transparently lease from public clouds to handle sudden spikes in demands. This could promote a responsive and reliable SaaS on the cloud. Another two important aspect of QoS, to which IT managers should pay more attention, related to human computer interaction (HCI), namely customization features and usability practice. In other words, the SaaS properties should focus not only on the pragmatic aspects, such as effectiveness and efficiency, but also adapt to the end users' 
preferences and perceptions, which are constantly volatile. In summary, six main hypotheses alongside seven sub-hypotheses were supported by the data, and hence accepted. Only one sub-hypothesis $(H 3 a)$ failed to reach any statistical significance and was therefore rejected. Two age-related sub-hypotheses were shown to have a reverse direction, namely $H 2 b$ and $H 3 b$ and therefore rejected.

Although several managerial implications were discussed, this research serves managers and academics alike. For example, validating the UTAUT model in the context of SaaS can be considered to be an important theoretical implication. Although most of the main relationships within the UTAUT model were validated, it was demonstrated that the moderating effects of gender on the relationship between SI and BI were insignificant. Despite the sensitivity of women towards others' expectations, this research revealed that men and women are equally influenced by their social structure to accept and use new technology. This finding contradicted the UTAUT model with regard to the moderating effect of gender on the SI-BI relationship. In addition, the experience gained from this study revealed different interaction patterns with regard to the moderating effect of age on the relationship between BI and both EE and SI. The findings herein suggest that increasing age reduces the effect of both $\mathrm{EE}$ and SI on BI, which is inconsistent with the UTAUT model [15]. Several explanations can possibly justify this inconsistency. Deeper analysis of the data showed that most of the elderly workers came from an IT background or higher managerial position; hence, they would be more confident with regard to the adoption of new technology, like SaaS. In particular, with an increasing confidence, the effect of effort-related concerns and social pressures associated with attitudes towards using SaaS were reduced. This finding is consistent with prior research on the acceptance of cloud computing in Saudi Arabia, namely the moderating effect of job domain [37, 51]. In summary, several managerial and theoretical implications were discussed and put forward to aid practitioners and researchers in the field of SaaS.

\subsection{Limitation and further research}

Although this research highlighted the belief factors that determine the acceptance of SaaS, several limitations were encountered, hence, recommendations for further research are now suggested.
For example, the sample selection process was influenced by the willingness of respondents to voluntarily participate. This incurred a sample selection bias, which decreases the sample representativeness of the population. Another limitation is that the survey was conducted using a single instrument at a single point in time, creating the possibility of common method variance. This kind of variance refers to the practice of collecting self-reported measures of several perceptual and belief factors from respondents, which cannot be verified by other means, and attempting to interpret the correlations between them [69]. In fact, selfreported measures lead to artefactual covariance, because they require working at a higher level of abstraction by asking for a summary of judgements, compared with reporting discrete events or a recalling certain events. Despite the limitations, this research opened new directions for further research. For example, the current assessment of QoS is rather abstract, and therefore an in-depth empirical analysis of QoS antecedents merits further investigation. Another suggestion for further research calls for investigating the acceptance of SaaS technology in consumer contexts by using the extended version of the UTAUT [25]. In summary, several limitations of this research have been discussed and new directions for further research recommended.

\section{Conclusion}

This paper examined the factors contributing to the adoption of SaaS. It drew upon prior research to develop a revised model based on the UTAUT. The proposed model offers a comprehensive explanation for SaaS adoption behaviour, by modelling QoS as a primary antecedent of BI, due to its role in online services. Furthermore, education was incorporated into the model as a moderating factor to fit the context of SaaS adoption in developing countries. The revised model was empirically examined using empirical data collected by means of an online questionnaire. Based on a survey of seven hundred and eighty-five $(n=785)$ internet users, results herein reveals that the UTAUT is a valid model through which to identify and analyse the factors affecting acceptance and use of SaaS. The SaaS adoption behaviour can be determined by PE, EE, SI, FC and QoS.

Acknowledgment

None. 
Conflicts of interest

The author has no conflicts of interest to declare.

References

[1] Lee SG, Chae SH, Cho KM. Drivers and inhibitors of SaaS adoption in Korea. International Journal of Information Management. 2013; 33(3):429-40.

[2] Janssen M, Joha A. Challenges for adopting cloudbased software as a service (saas) in the public sector. In proceedings of European conference on information system (ECIS) 2011. AIS Electronic Library.

[3] Colombus L. Roundup of cloud computing forecast and market estimates. Forbes Magazine. http://www.forbes.com/sites/louiscolumbus/2015/01/2 4/roundup-of-cloud-computing-forecasts-and-marketestimates-2015. Accessed 11 July 2015.

[4] Pawar PS, Sajjad A, Dimitrakos T, Chadwick DW. Security-as-a-service in multi-cloud and federated cloud environments. In IFIP international conference on trust management 2015 (pp. 251-61). Springer International Publishing.

[5] Wu S, Wortmann H, Tan CW. A pricing framework for software-as-a-service. In fourth international conference on innovative computing technology 2014 (pp. 152-7). IEEE.

[6] Araujo VM, Vázquez JA, Cota MP. A framework for the evaluation of SaaS impact. International Journal in Foundations of Computer Science \& Technology. 2014; 4(3):1-16.

[7] Benlian A, Hess T. Opportunities and risks of software-as-a-service: findings from a survey of IT executives. Decision Support Systems. 2011; 52(1):232-46.

[8] Mangula IS, van de Weerd I, Brinkkemper S. Why do companies adopt or reject SaaS? looking at the organizational aspect. PACIS 2015 proceedings 2015. AIS Electronic Library (AISeL).

[9] Yang Z, Sun J, Zhang Y, Wang Y. Understanding SaaS adoption from the perspective of organizational users: A tripod readiness model. Computers in Human Behavior. 2015; 45:254-64.

[10] Safari F, Safari N, Hasanzadeh A. The adoption of software-as-a-service (SaaS): ranking the determinants. Journal of Enterprise Information Management.2015; 28(3):400-22.

[11] Yang CC, Chou SW. Understanding the success of software-as-a-service (SaaS)-the perspective of postadoption use. PACIS 2015 proceedings 2015. AIS Electronic Library (AISeL).

[12] Tan X, Kim Y. User acceptance of SaaS-based collaboration tools: a case of Google docs. Journal of Enterprise Information Management. 2015; 28(3):42342.

[13] Marston S, Li Z, Bandyopadhyay S, Zhang J, Ghalsasi A. Cloud computing-the business perspective. Decision Support Systems. 2011; 51(1):176-89.

[14] Gonçalves V, Ballon P. Adding value to the network: Mobile operators' experiments with Software-as-aService and Platform-as-a-Service models. Telematics and Informatics. 2011; 28(1):12-21.
[15] Venkatesh V, Morris MG, Davis GB, Davis FD. User acceptance of information technology: toward a unified view. MIS Quarterly. 2003:425-78.

[16] Ajzen I, Fishbein M. Belief, attitude, intention and behavior: an introduction to theory and research. Reading, MA: Addison-Wesley; 1975.

[17] Davis FD. Perceived usefulness, perceived ease of use, and user acceptance of information technology. MIS Quarterly. 1989:319-40.

[18] Davis FD, Bagozzi RP, Warshaw PR. Extrinsic and intrinsic motivation to use computers in the workplace1. Journal of Applied Social Psychology. 1992; 22(14):1111-32.

[19] Ajzen I. The theory of planned behavior. Organizational Behavior and Human Decision Processes. 1991; 50(2):179-211.

[20] Taylor S, Todd PA. Understanding information technology usage: a test of competing models. Information Systems Research. 1995; 6(2):144-76.

[21] Thompson RL, Higgins CA, Howell JM. Personal computing: toward a conceptual model of utilization. MIS Quarterly. 1991; 15(1):125-43.

[22] Moore GC, Benbasat I. Development of an instrument to measure the perceptions of adopting an information technology innovation. Information Systems Research. $1991 ; 2(3): 192-222$.

[23] Compeau DR, Higgins CA. Application of social cognitive theory to training for computer skills. Information Systems Research. 1995; 6(2):118-43.

[24] Williams MD, Rana NP, Dwivedi YK. The unified theory of acceptance and use of technology (UTAUT): a literature review. Journal of Enterprise Information Management. 2015; 28(3):443-88.

[25] Venkatesh V, Thong JY, Xu X. Consumer acceptance and use of information technology: extending the unified theory of acceptance and use of technology. MIS Quarterly. 2012; 36(1):157-78.

[26] Alharbi ST. Trust and acceptance of cloud computing: A revised UTAUT model. In international conference on computational science and computational intelligence (CSCI) 2014 (pp. 131-4). IEEE.

[27] Alotaibi MB. Exploring users' attitudes and intentions toward the adoption of cloud computing in Saudi Arabia: an empirical investigation. Journal of Computer Science. 2014; 10(11):2315-29.

[28] Brown SA, Dennis AR, Venkatesh V. Predicting collaboration technology use: Integrating technology adoption and collaboration research. Journal of Management Information Systems. 2010; 27(2):9-54.

[29] Lin CS, Wu S. Exploring the impact of online service quality on portal site usage. In proceedings of 35 th annual Hawaii international conference on system sciences (HICSS) 2002 (pp. 2654-61). IEEE.

[30] Hu PJ, Brown SA, Thong JY, Chan FK, Tam KY. Determinants of service quality and continuance intention of online services: the case of eTax. Journal of the American Society for Information Science and Technology. 2009; 60(2):292-306.

[31] Akter S, D'Ambra J, Ray P. Service quality of mHealth platforms: development and validation of a 
hierarchical model using PLS. Electronic Markets. 2010; 20(3-4):209-27.

[32] Çelik HE, Yilmaz V. Extending the technology acceptance model for adoption of e-shopping by consumers in Turkey. Journal of Electronic Commerce Research. 2011; 12(2):152-64.

[33] Chang MY, Pang C, Tarn JM, Liu TS, Yen DC. Exploring user acceptance of an e-hospital service: an empirical study in Taiwan. Computer Standards \& Interfaces. 2015; 38:35-43.

[34] Alharthi A, Yahya F, Walters RJ, Wills G. An overview of cloud services adoption challenges in higher education institutions 2015 (pp. 102-9).

[35] Alawadhi S, Morris A. The use of the UTAUT model in the adoption of E-government services in Kuwait. In proceedings of the Hawaii international conference on system sciences 2008 (pp. 219-29). IEEE.

[36] Gombachika H, Monawe M. Correlation analysis of attitudes towards SMS technology and blood donation behaviour in Malawi. Journal of Health Informatics in Developing Countries. 2011; 5(2):259-72.

[37] Alharbi ST. Users' acceptance of cloud computing in Saudi Arabia: an extension of technology acceptance model. International Journal of Cloud Applications and Computing. 2012; 2(2):1-11.

[38] Shi YD, Yang CF, Wei HE. Antecedents and influence factors of Macao residents' acceptance intention of sport easy program. In international conference on engineering, management science and innovation (ICEMSI) 2013 (pp. 1-3). IEEE.

[39] Wu WW. Developing an explorative model for SaaS adoption. Expert Systems with Applications. 2011; 38(12):15057-64.

[40] Chen LY. Determinants of Software-as-a-Service adoption and intention to use for enterprise applications. International Journal of Innovation and Applied Studies. 2015; 10(1):138-48.

[41] Venkatesh V, Morris MG, Ackerman PL. A longitudinal field investigation of gender differences in individual technology adoption decision-making processes. Organizational Behavior and Human Decision Processes. 2000;83(1):33-60.

[42] Barnett RC, Marshall NL. The relationship between women's work and family roles and their subjective well-being and psychological distress. In women, work, and health 1991 (pp. 111-36). Springer US.

[43] Al-Qeisi K, Dennis C, Hegazy A, Abbad M. How viable is the UTAUT model in a non-western context? International Business Research. 2015; 8(2):204-19.

[44] Morris MG, Venkatesh V. Age differences in technology adoption decisions: Implications for a changing work force. Personnel Psychology. 2000; 53(2):375-403.

[45] Su YC, Hwang CS, Chiang PY. A study of user acceptance toward recommender systems of the shopping websites. Advances in Information Sciences and Service Sciences. 2013; 5(11):150-8.

[46] Park J, Yang S, Lehto X. Adoption of mobile technologies for Chinese consumers. Journal of Electronic Commerce Research. 2007; 8(3):196-206.
[47] Zmud RW. Individual differences and MIS success: a review of the empirical literature. Management Science. 1979; 25(10):966-79.

[48] Dennis C, Merrilees B, Jayawardhena C, Tiu Wright L. E-consumer behaviour. European Journal of Marketing. 2009; 43(9/10):1121-39.

[49] Venkatesh V, Davis FD. A theoretical extension of the technology acceptance model: four longitudinal field studies. Management Science.2000; 46(2):186-204.

[50] Hu HF, Al-Gahtani SS, Hu PJ. Examining gender effects in technology acceptance by Arabian workers: a survey study. PACIS 2010 proceedings 2015 (pp. 85-97). AIS Electronic Library (AISeL).

[51] Al-Gahtani SS, Hubona GS, Wang J. Information technology (IT) in Saudi Arabia: culture and the acceptance and use of IT. Information \& Management. 2007; 44(8):681-91.

[52] Vatanasakdakul S, Aoun C, Li Y. AIS in Australia: UTAUT application and cultural implication. Australasian conference on information systems 2010.

[53] Hall DT, Mansfield R. Relationships of age and seniority with career variables of engineers and scientists. Journal of Applied Psychology. 1975; 60(2):201-10.

[54] Alba JW, Hutchinson JW. Dimensions of consumer expertise. Journal of Consumer Research. 1987; 13(4):411-54.

[55] Liu L, Ma Q. The impact of service level on the acceptance of application service oriented medical records. Information \& Management. 2005; 42(8):1121-35

[56] Park E, Del Pobil AP. Modeling the user acceptance of long-term evolution (LTE) services. Annals of Telecommunications-Annales

Des Télécommunications. 2013; 68(5-6):307-15.

[57] Park E, Kim KJ. An integrated adoption model of mobile cloud services: exploration of key determinants and extension of technology acceptance model. Telematics and Informatics. 2014; 31(3):376-85.

[58] Bryman A, Bell E. Business research methods. Oxford University Press, USA; 2015.

[59] Markus KA. Principles and practice of structural equation modeling by Rex B. Kline. Structural Equation Modeling: A Multidisciplinary Journal. 2012;19(3):509-12.

[60] Alexandrov A. Characteristics of single-item measures in Likert scale format. The Electronic Journal of Business Research Methods. 2010; 8(1):1-12.

[61] Burkon L. Quality of service attributes for software as a service. Journal of Systems Integration. 2013; 4(3):38-47.

[62] Barclay D, Higgins C, Thompson R. The partial least squares (PLS) approach to causal modeling: personal computer adoption and use as an illustration. Technology Studies. 1995; 2(2):285-309.

[63] Falk RF, Miller NB. A primer for soft modeling. University of Akron Press; 1992.

[64] Hair JF. Multivariate data analysis. Pearson College Division; 2010. 
[65] Lucas RE, Diener E, Suh E. Discriminant validity of well-being measures. Journal of Personality and Social Psychology. 1996; 71(3):616-28.

[66] Carmines EG, McIver JP. Analyzing models with unobserved variables: analysis of covariance structures. Social Measurement: Current Issues. 1981; 65-115.

[67] Byrne BM. Structural equation modeling with LISREL, PRELIS, and SIMPLIS: basic concepts, applications, and programming. Psychology Press; 2013.

[68] Bagozzi RP, Yi Y. On the evaluation of structural equation models. Journal of the Academy of Marketing Science. 1988; 16(1):74-94.

[69] Podsakoff PM, Organ DW. Self-reports in organizational research: problems and prospects. Journal of Management. 1986; 12(4):531-44.

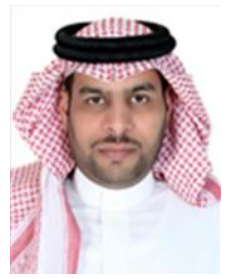

Mutlaq B. Alotaibi is an Associate Professor of Information Systems at Al Imam Mohammad Ibn Saud Islamic University (IMSIU). In 2010, he was appointed Head of the IS Department. In 2012, he was appointed as the Vice Dean for Academic Affairs at the College of Computer and Information Sciences. His main research interests are in the area of interactive systems, particularly in multimodal interaction and adaptive user interfaces. He is also interested in IS research, particularly consumer behaviour, and in the application of user acceptance of technologies. He has publications in the fields of, e-business and e-commerce, customer knowledge management, customer relationship management, cloud computing, mobile computing, and usability heuristics.

Email: motaibi@imamu.edu.sa 